Hydraulic Engineering Repository

Ein Service der Bundesanstalt für Wasserbau

Wolters, Guido; Rudolph, Daniel; Hofland, Bas; Verheij, Henk

On the Behaviour of Open Filters Under Wave Loading

Verfügbar unter / Available at:

https://hdl.handle.net/20.500.11970/100247

Vorgeschlagene Zitierweise / Suggested citation:

Wolters, Guido; Rudolph, Daniel; Hofland, Bas; Verheij, Henk (2010): On the Behaviour of Open Filters Under Wave Loading. In: Burns, Susan E.; Bhatia, Shobha K.; Avila, Catherine M. C.; Hunt, Beatrice E. (Hg.): Proceedings 5th International Conference on Scour and Erosion (ICSE-5), November 7-10, 2010, San Francisco, USA. Reston, Va.: American Society of Civil Engineers. S. 142-151. 


\title{
On the Behaviour of Open Filters Under Wave Loading
}

\author{
G. Wolters ${ }^{1}$, D. Rudolph ${ }^{2}$, B. Hofland ${ }^{3}$ and H. Verheij ${ }^{4}$
}

${ }^{1}$ Deltares | Delft Hydraulics, P.O. Box 177, 2600 MH Delft, The Netherlands, PH +31(0)883358318, email: guido.wolters@, deltares.n1

${ }^{2}$ Deltares | Delft Hydraulics, P.O. Box 177, $2600 \mathrm{MH}$ Delft, The Netherlands, PH $+31(0) 883358362$, email: daniel.rudolph@deltares.nl

${ }^{3}$ Deltares | Delft Hydraulics, P.O. Box 177, 2600 MH Delft, The Netherlands, PH +31(0)883358196, email: bas.hoflandia deltares.nl

${ }^{4}$ Delft University of Technology and Deltares | Delft Hydraulics, P.O. Box 177, 2600 MH Delft, The Netherlands, PH +31(0)883358137, email: henk.verheij@deltares.nl

\begin{abstract}
The design of granular open filters under wave and current loading has raised increasing interest in recent years, especially under marine contractors and consultants. Proper guidelines on the design of open filters, which allow an acceptable and predictable loss of base material under wave and current loading, could lead to significant cost and material savings, and to a more practical application of filters in the field.

In order to improve the knowledge on the behaviour of granular open filters under wave loading, laboratory experiments have been conducted in the Scheldt flume of Deltares | Delft Hydraulics. This paper summarizes the model set-up, test programme and test results. The results include erosion (transport) rates and filter settling for open filter materials on sand.
\end{abstract}

\section{LITERATURE REVIEW}

Granular filters typically employed in coastal engineering fulfill several functions. They prevent e.g. the erosion (washing out) of finer base material or sublayers due to waves and currents, contribute to the energy dissipation by turbulent flow through void spaces and provide drainage. Granular filters can be designed as geometrically tight filters or geometrically open filters.

The design of geometrically tight filters (no material washout) is relatively simple, but often an unnecessary high number of filter layers and material volume is required. Furthermore, geometrically tight filters are often difficult to realize in the field because of quarry material limitations and when the structure is constructed underwater.

An alternative is a geometrically open filter. In this case the filter is designed in such a manner that the hydraulic loading is too low to initiate significant erosion of the base material. Limited settlement is often permitted in the field. Typical applications of open filters include e.g. offshore bed protections and toe \& slope configurations of coastal structures.

The allowed settlement depends on the structure type. For breakwaters and revetments even small amounts of toe settlement can endanger the stability of the armour layer by loosening the bonds between interlocked armour units or placed 
stone revetments. This can lead to the failure of the structure as a whole (see e.g. CIRIA | CUR | CETMEF 2007).

Since 1980 a lot of research has been conducted on interface stability and initiation of transport in filters which have resulted in varying formulae and design diagrams (see e.g. Bakker et al. 1994, Klein Breteler 1992, Verheij et al 2008, Sumer et al. 2001, Dixen et al. 2008). These research studies have mainly focused on stationary, non-cyclic flow at the point of transport initiation. There is only very limited data on base material transport or induced filter settlement and the data which exist focus on non-cyclic flow conditions. Only Dixen et al (2008) report some findings on transport initiation as function of wave characteristics for a single and multiple layers of rock.

For base material transport through filters only two transport models are known to the authors; other available transport models (see e.g. Van Rijn, 2005) are not applicable to sand transport within filters. These are the transport models of Klein Breteler et al. $(1989,1992)$ and Den Adel et al. $(1992,1994)$.

Both models describe the macroscopic transport of base materials through filters. Each has its own restrictions. Both are applicable only for stationary and (fully) turbulent currents and macroscopic transport processes. Microscopic processes (description of the individual particle behaviour) are not included. Den Adel's model is only applicable for bedload transport (and can thus not be used in the suspended transport regime). Both models provide a transport estimate which is accurate to an order of magnitude.

The fundamental applicability of the models for cyclic flows (waves) and larger wave periods $T>2-5$ s is assumed (see also Dixen et al., 2008) but has not been verified. Basis for this assumption is that the initiation of transport occurs under similar conditions for both cyclic and stationary conditions.

The transport model of Den Adel includes, because of its many parameters (e.g. densities $\rho$ and $\mu$, particle velocity, pick-up- and catchfrequency, several proportionality constants), several uncertainties and imponderabilia. Not all of these uncertainties can be quantified in the model. Furthermore, some fundamental problems were found which will be discussed later in this paper.

The model of Klein Breteler is comparatively simplified but has the advantage of less parameters and proportionality constants. The latter model has been used in the present study. While the transport model of Klein Breteler et al. will be described shortly in the following, it is referred to the literature for the model of Den Adel et al. The model is too elaborate to be captured within the constraints of this paper.

\section{Macroscopic transport model}

Klein Breteler (1992) introduced the following empirical transport formulae for macroscopic transport within filters (stationary current, homogeneous base material):

$$
T_{1}=\rho_{s} \cdot p_{1} \cdot\left(i / i_{c r}-1\right)^{1.25} \quad \text { or } \quad T_{2}=\rho_{s} \cdot p_{2} \cdot\left(\left(u_{f} / u_{f, c r}\right)^{2}-1\right)^{1.5}
$$


where

$$
\begin{aligned}
& \mathrm{T}_{\mathrm{i}}=\text { transport rate in }(\mathrm{kg} / \mathrm{m} / \mathrm{s}) \\
& \rho_{\mathrm{s}}=\text { density of transported material }\left(\mathrm{kg} / \mathrm{m}^{3}\right) \\
& \mathrm{u}_{\mathrm{f}, \mathrm{r}}=\text { critical filter velocity }(\mathrm{m} / \mathrm{s}) \\
& \mathrm{i}_{\mathrm{i} r}=\text { critical hydraulic gradient }(-) \\
& \mathrm{p}_{\mathrm{i}}=\text { transport intensity }\left(\mathrm{m}^{3} / \mathrm{m} / \mathrm{s}\right)
\end{aligned}
$$

These formulae are based on the assumption of a turbulent current, i.e. the hydraulic gradient is proportional to the square of the filter velocity. Formula (2), based on $u_{f, c r}$, is derived from the classical formula of Meyer-Peter and Mueller for bedload transport in free surface flows.

The value of the transport intensity $\mathrm{p}_{\mathrm{i}}$ seems to be independent of the diameter of the transported material and was found by Klein Breteler (dependent on the formula used) to be in the range of

$$
\mathrm{p}_{\mathrm{i}}=0.6-9.0 \times 10^{-6} \mathrm{~m}^{2} / \mathrm{s} \quad \text { with a best fit for } \quad \mathrm{p}_{\mathrm{i}}=1.5 \times 10^{-6} \mathrm{~m}^{2} / \mathrm{s}
$$

The critical filter velocities were found to be in the range of $u_{f, c r i t}=0.037-$ $0.102 \mathrm{~m} / \mathrm{s}$. Tested base materials had a median sieve diameter of $\mathrm{D}_{50 . \mathrm{b}}=0.16 \mathrm{~mm}$ and $\mathrm{D}_{50, \mathrm{~b}}=0.82 \mathrm{~mm}$ and filter material diameters between $\mathrm{D}_{15, \mathrm{f}}=4.2-83.8 \mathrm{~mm}(15 \%$ values of filter sieve curve).

Further results of the study by Klein Breteler (1992) include:

- Influence of filter material diameter $\left(\mathrm{D}_{\mathrm{f} .50}\right)$ : The critical transport velocities for fine base material seem to be dependent on the diameter of the filter material. However, this does not seem to be the case for coarser base material (e.g. $\mathrm{D}_{50,6}=0.82 \mathrm{~mm}$ ).

- Influence of material distribution: The amount of transported material is strongly dependent on the size distribution of the material (sieve curve).

- It is assumed that the base material is relatively homogeneous. If this is not the case, the transport per class of diameters becomes relevant (for each material class a different $\mathrm{u}_{\mathrm{f}, \mathrm{cr}}$ is found). Total transport can then be described as the sum of transport over all classes. For this case a stochastic model was proposed, see e.g. Klein Breteler (1992).

\section{Critical filter velocities and gradients}

Theoretically the critical filter velocity $\mathrm{u}_{\mathrm{f}, \mathrm{cr}}$ for the initiation of base particle motion (stationary current) is given by Den Adel (1992) and Klein Breteler (1989) as:

$u_{f, c r}=\left[\frac{n_{f}}{c_{10}}\left[\frac{D_{15, f}}{v_{w}}\right]^{c_{9}} \sqrt{\psi_{s} \cdot \Delta \cdot g \cdot D_{50 . b}}\right]^{1 /\left(1-c_{9}\right)}$

with 


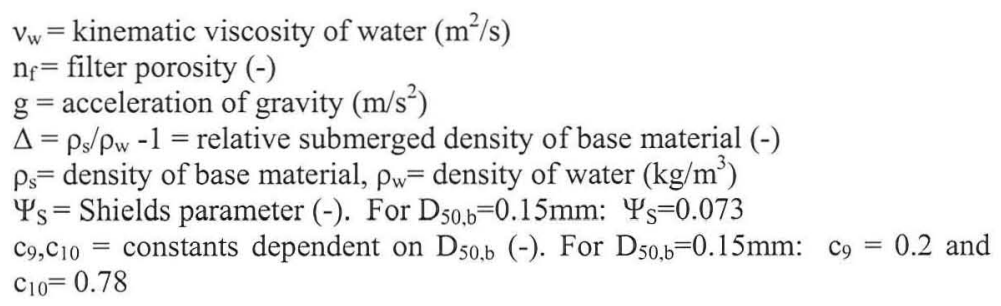

The critical hydraulic gradient for initiation of transport can be calculated from De Graauw (1983, stationary current):

$i_{c r}=\left[\frac{0.06}{n_{f}^{3} D_{15, f}^{4 / 3}}+\frac{n_{f}^{5 / 3} D_{15, f}^{1 / 3}}{1000 D_{50, b}^{5 / 3}}\right] v_{* c r}^{2}$

using:

$v_{* c r}=1.3 D_{50, b}^{0.57}+8.3 \cdot 10^{-8} D_{50, b}^{-1.2}$

Please note that relations (4) and (5) are dimension-dependent. For cyclic flows (waves) it is generally assumed that the critical value of the hydraulic gradient (and of the filter velocity) is of the same order of magnitude as for stationary currents.

\section{MODEL SET-UP} the model:

The following boundary conditions have been chosen for the initial set-up of

- Fully turbulent conditions $\left(\mathrm{Re}^{*}=\mathrm{u}_{2 \%} \mathrm{D}_{\mathrm{n} 50, \mathrm{f}} / v_{\mathrm{w}}>>1000, \mathrm{u}_{2} \%=\right.$ velocity directly above the filter exceeded by $2 \%$ of waves)

- Low transport regime (bedload transport): Since transport by suspension is likely to cause a fast damage progression in open filters under prototype conditions (e.g. for breakwater toes) which can result in ultimate structure failure, the focus was initially laid on bedload transport.

- Uni-directional measurement of sand transport: To create sand transport under cyclic conditions irregular (non-sinusoidal) waves need to be employed. Under pure sinusoidal waves effective transport will be minimal since the base material moves back and forth around its original location without any significant displacement (advection). Using $2^{\text {nd }}$ order Stokes waves of varying steepness a net-transport in wave direction was achieved.

- To prevent boundary effects due to seabed lowering (induced by filter settlement) it was decided to stop the test if sea bed lowering of more than $2 \mathrm{~cm}$ was measured. Otherwise the seabed was not rebuilt between tests. 
The set-up of the model is shown in Figures 1 and 2. It consists of a submerged filter construction on a sand bed which is subjected to irregular wave loading with a JONSWAP wave spectrum. Second order (Stokes) waves have been employed to allow the simulation of the correct wave form and wave steepness. Measured were base material (sand) transport, filter settlement using a mechanical profiler, pore pressures and pressure gradients in filter and sand bottom and the $\mathrm{x}-\mathrm{z}$ velocities directly above the filter.

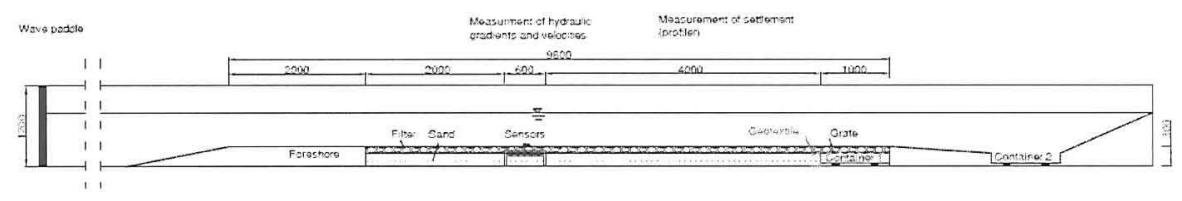

Figure 1. Model set-up in the Scheldt flume of Deltares|Delft Hydraulics
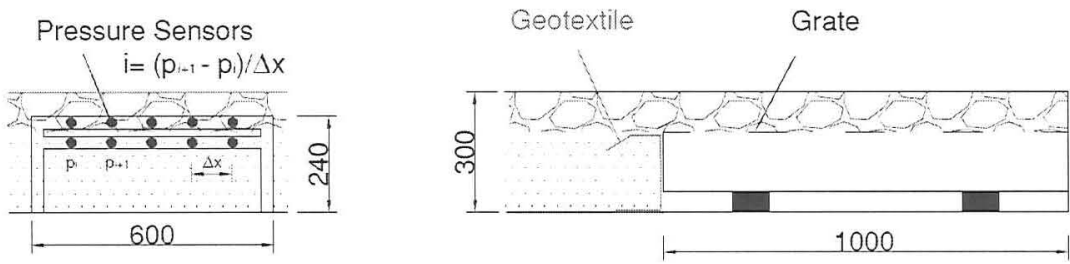

Figure 2. Frame for pressure measurements

A concrete foreshore of $0.3 \mathrm{~m}$ height was used in which the filter layer of $\mathrm{d}=5.5$ or $10 \mathrm{~cm}$ thickness and the sand layer of $\mathrm{d}_{\mathrm{s}}=24.5$ or $20 \mathrm{~cm}$ thickness were embedded. The horizontal concrete section and the first part of the filter section in front of the measurement area (length $\mathrm{L}=10 \mathrm{~h}, \mathrm{~h}=$ water depth) allowed the turbulent flow conditions within the filter layer to become fully developed before any measurement was conducted. Behind the test section a free space of also $10 \mathrm{~h}$ was left in front of the wave damper. The chosen thickness of the sand layer was sufficiently deep so that the flume bottom did not significantly affect the pore pressure distribution within the sand bed. The chosen filter thickness varied between 3.5 and 2 $D_{n 50, f}\left(D_{n 50, f}\right.$ is the nominal median diameter of the filter material) to allow for filter velocities above critical at the filter-sand interface.

The sand layer was carefully installed in a wet state within the wave flume and smoothed. Before testing the flume was filled with water and left for a day to allow all remaining air bubbles to leave the sand. Prior to actual testing the sand bed was exposed to 2 hours of low wave energy. Between tests a minimum layer of water was always kept above the sand bed.

The employed water within the wave flume was stored in a second tank between reconstructions / tests. This way it was ensured that the same water, that was 
saturated with fine sand particles after the first test, was used for all tests and that no model effects were introduced by using (clean) fresh water in each test.

The transported sand is collected in two containers behind the filter section: The first container collects the transported sand through the filter and along the bed (bedload) and the second any suspended material $(>20-30 \mu \mathrm{m})$. Finer material $(>20-$ $30 \mu \mathrm{m})$ could not be accurately measured since it mainly remained suspended in the water after testing. After each test the suspended sand which settled on the wave damper (behind the second container) was flushed back into the $2^{\text {nd }}$ container. Sand transport in opposite direction to the waves was measured by collecting it from the foreshore.

Between filter layer and the first sand container a geotextile was placed. A geotextile was also placed on the first part of the sand container. The geotextile ensured that the sand particles at the boundary between sand bed and container would not simply drop into the container during the oscillatory wave motion but were actually displaced (transported). The horizontal length of the geotextile was 6 or $10 D_{n 50, f}$. Secondly, the geotextile was used to prevent significant boundary affects due to possible scouring in front of the sand container.

The collected sand samples $(>20-30 \mu \mathrm{m})$ were dried, weighed and analyzed (sieving curve) to verify which particle size ranges were transported.

Measurements were performed of the incident waves, the filter settlement (mechanical profiler, using 3 separate rows), pressures ( 2 rows of 5 pressure sensors each, $2.5 \mathrm{~cm}$ above and below the filter-sand interface), $\mathrm{x}$-z-particle velocities (EMS, $2.5 \mathrm{~cm}\left(\sim 1 \mathrm{D}_{\mathrm{n} 50, \mathrm{f}}\right)$ above the seabed), base material transport (collected in sand containers, see above), ripple length, heights and sand movements along the seabed. Videos and photo recordings of all tests were made.

\section{Materials}

The following materials have been used in the tests:

- $\mathrm{D}_{\mathrm{n} 50, \text { sand }}=0.13 \mathrm{~mm}, \mathrm{D}_{\mathrm{n} 50, \mathrm{filter}}=20 \mathrm{~mm}$ and $30 \mathrm{~mm}, \mathrm{D}_{\mathrm{n} 50, \mathrm{f}} / \mathrm{D}_{\mathrm{n} 50, \mathrm{~b}}=150-230$

- A wide grading of the filter material was chosen $\left(M_{85} / M_{15}=3.37\right)$ since these are often used in toe and offshore structures.

The porosity of sand and filter material was estimated from the sieving curves to $n_{s}=0.35$ and $n_{f}=0.44$ respectively. This results in an installed dry, bulk mass density of about $1700 \mathrm{~kg} / \mathrm{m}^{3}$ (sand) respectively $1500 \mathrm{~kg} / \mathrm{m}^{3}$ (filter).

Based on the previously introduced formula for the critical filter velocity and the critical hydraulic gradient the following critical values can be calculated for $\mathrm{D}_{\mathrm{f}, 15}$ $=20-30 \mathrm{~mm}$ (stationary current): $\mathrm{u}_{\mathrm{f}, \mathrm{cr}} \approx 0.02-0.03 \mathrm{~m} / \mathrm{s}$ and $\mathrm{i}_{\mathrm{cr}}=0.06-0.07$.

\section{TEST PROGRAMME}

The test programme, see Table 1 , included tests with varying wave steepness $\left(s_{o p}=0.004-0.027\right)$, varying filter thickness $\left(d=2 D_{n 50, f}\right.$ and $\left.3.5 D_{n 50, f}\right)$ and varying filter material ( $D_{n 50, f}=20 \mathrm{~mm}$ and $30 \mathrm{~mm}$ ). The base material (sand) and the water depth above the open filter $(\mathrm{h}=0.4 \mathrm{~m})$ were kept constant during all tests. This corresponds to values of $d / D_{n 50, f}=1.8,2.8,3.3$ and $d / h=0.14$ and 0.25 . Tests were conducted for turbulent conditions ( $\operatorname{Re}^{*}>4000$, based on $\mathrm{u}_{2} \%$ ), $\mathrm{KC}=\mathrm{u}_{2 \%} \mathrm{~T}_{\mathrm{m}} / \mathrm{n}_{\mathrm{f}} \mathrm{D}_{\mathrm{n} 50, \mathrm{P}}>>40$ and 
mobility numbers of $\theta=\mathrm{u}_{2 \%}{ }^{2} / \mathrm{g} / \Delta / \mathrm{D}_{50, \mathrm{~b}}>26.5$. Testing was conducted for wave loading only. The test duration $(\mathrm{t})$ varied between tests based on the observed base material transport. Since the initial tests did not show much sand transport the test duration was continuously increased up to 6 hours. The total test length varied between 1000 waves and 6 hours ( $>10000$ waves).

Tests T01-T04 (see observation section) are not presented here since they proved to be below the threshold for transportation.

Table 1. Testing programme

\begin{tabular}{|c|c|c|c|c|c|c|c|c|c|c|c|}
\hline & \multicolumn{11}{|c|}{ Test programme } \\
\hline & $\mathrm{D}_{15, \mathrm{l}}(\mathrm{mm})$ & $\mathrm{D}_{\mathrm{n} 50, \mathrm{r}}(\mathrm{mm})$ & $d(m)$ & $h(m)$ & $\mathrm{H}_{\mathrm{s}}(\mathrm{m})$ & $\mathrm{T}_{p}(\mathrm{~s})$ & $s_{o p}(-)$ & $t$ (hrs) & $\operatorname{Re}^{*}(-)$ & $K C(-)$ & $\theta(-)$ \\
\hline T05 & 28 & 30 & 0,1 & 0,4 & 0,10 & 2,09 & 0,015 & 6 & 4913 & 35 & 27 \\
\hline T06 & 28 & 30 & 0,1 & 0,4 & 0,14 & 2,52 & 0,014 & 6 & 7181 & 61 & 57 \\
\hline T07 & 28 & 30 & 0,1 & 0,4 & 0,17 & 5,41 & 0.004 & 2 & 16444 & 300 & 297 \\
\hline T08 & 28 & 30 & 0,055 & 0,4 & 0,14 & 2,52 & 0,014 & 6 & 8006 & 68 & 70 \\
\hline TO9 & 28 & 30 & 0,055 & 0.4 & 0,14 & 1.80 & 0,027 & 6 & 5925 & 36 & 39 \\
\hline $\mathrm{T} 10$ & 28 & 30 & 0.055 & 0.4 & 0,16 & 5,10 & 0.004 & 2 & 16069 & 276 & 284 \\
\hline $\mathrm{T} 11$ & 19 & 20 & 0,055 & 0.4 & 0,14 & 2,52 & 0.014 & 6 & 5088 & 97 & 64 \\
\hline $\mathrm{T} 12$ & 19 & 20 & 0,055 & 0.4 & 0,14 & 1.81 & 0.027 & 6 & 4000 & 55 & 40 \\
\hline $\mathrm{T} 13$ & 19 & 20 & 0,055 & 0.4 & 0.16 & 5.10 & 0.004 & 2 & 10963 & 424 & 297 \\
\hline
\end{tabular}

\section{OBSERVATIONS AND ANALYSIS}

The following observations were made during testing:

- The tests were originally set-up to investigate bedload and suspended load transport separately (focusing in first instance on bedload transport), based on the $\mathrm{u}_{\mathrm{cr}}$ - criteria developed by Den Adel (1992). However, it became apparent during testing that these two regimes could not be separated, since significant base material transport could only be realized once the filter velocities were far above the critical velocity and once base material was also suspended in the water column.

- The observed base material transport for wave loading alone was very low (and appears insignificant compared to transport by current) even for large near-bed velocities and hydraulic gradients ( $\left.\mathrm{i}_{2 \%} / \mathrm{i}_{\mathrm{cr}}=1-7, \mathrm{u}_{2} \% / \mathrm{u}_{\mathrm{f}, \mathrm{cr}}=10-40\right)$, see Figures 3 \& 4. It was observed that while the hydraulic gradients (horizontally measured in the filter between pressure sensors) were sufficiently high to produce initiation of motion around its rest position and suspension of materials, most of the bed material remained in its original vicinity.

- The largest transport rates were observed for waves of low steepness $\left(\mathrm{s}_{\mathrm{op}}=0.004\right)$. These waves caused the largest forces on the seabed $(\theta \sim 300)$.

- As expected a decrease in sand material transport was found for smaller filter stone diameters (for $\mathrm{D}_{\mathrm{n} 50}=20 \mathrm{~mm}$ only about half of the volume was transported as for $\mathrm{D}_{\mathrm{n} 50}=30 \mathrm{~mm}$ ), see Figure $3 \& 4$. A reduction of the filter thickness of 3.5 $D_{n 50}$ to $2 D_{n 50}$ resulted however in a $20-60 \%$ reduction in material transport in all tests. This finding seems somewhat counterintuitive (and should be verified in further tests). A possible explanation is given later in the paper. Furthermore, a steady increase in transport was found for increasing $\mathrm{KC}$ values $(\mathrm{KC}=40-450$, $\mathrm{KC}$ is proportional to the stroke of the motion at the seabed).

- The tests showed that the base material distribution (sieving curve) changed during transport. Whereas the original sand had a median particle size of $D_{50, b}=152 \mu \mathrm{m}$, the particle size of the transported bedload material was $D_{50, b}=142$ 
$\mu \mathrm{m}$ and that of the suspended load $\mathrm{D}_{50, \mathrm{~b}}=104 \mu \mathrm{m}$. The heaviest sand particles were left behind during bedload transport and only the lighter particles were transported in suspended mode.

It was observed that finer sand particles were entrained into the water column (particles $<20-30 \mu \mathrm{m}$ ) very quickly, clouding the water. Most of this material was so fine that it remained suspended in the water column even days after testing.
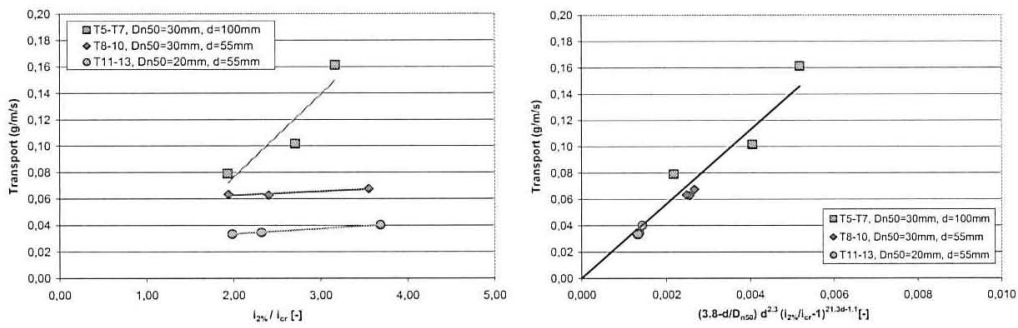

Figure 3. Transport vs. hydraulic gradient
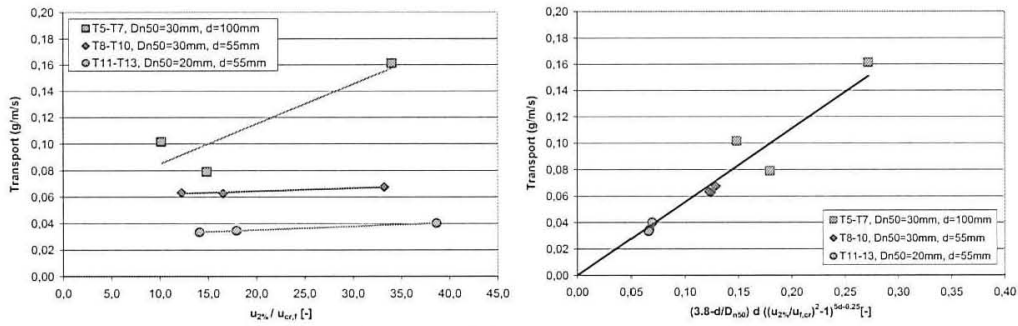

Figure 4. Transport vs. velocity

- Initiation of motion was first observed for $\mathrm{H}_{\mathrm{s}}=0.06 \mathrm{~m}, \mathrm{i}_{2 \%}=0.1, \mathrm{u}_{2} \%=0.12 \mathrm{~m} / \mathrm{s}$, $\mathrm{KC}=15$ ). Measurable material transport was first observed for wave heights of $\mathrm{H}_{\mathrm{s}}=0.1 \mathrm{~m}$ (test $\mathrm{T} 5, \mathrm{i}_{2} \%=0.15, \mathrm{u}_{2} \%=0.25 \mathrm{~m} / \mathrm{s}, \mathrm{KC}=35$ ). Dense base material clouds were observed within the filter. At this stage bed ripples became fully formed with heights of $1-2 \mathrm{~cm}$ and $7-17 \mathrm{~cm}$ length. The water within the flume appeared completely saturated with fine particles.

- Practically no transport along the bed surface was observed. The measured transport was due to the suspended material clouds within the filter layer, which moved through the filter. This transport process is in conflict with the bedload transport model of Den Adel (1992), which describes horizontal base material movement (particle by particle) along the sand-filter interface (no entrainment in the water column). Observed was however collective (cloud) material movement in wave direction. It appears therefore that den Adel's model (for stationary currents) cannot be employed for base material transport under waves. 


\section{Filter settlement}

The measured deviations in filter profile are mainly caused by ripple formation and ripple displacement at the sand-filter interface, actual settling effects were very small due to the low amount of base material transport. Based on the measured filter displacement a cumulative filter settlement of $3 \mathrm{~mm}, 1.3 \mathrm{~mm}$ and $1.1 \mathrm{~mm}$ was determined over the measurement area of $4.6 \mathrm{~m} \mathrm{x} 1 \mathrm{~m}$ (after tests T7, T10 and T13).

Unfortunately the filter settlement was too small for further analysis and is therefore not considered here any further.

\section{Base material transport}

It appears that both filter thickness and filter stone diameter have a significant influence on base material transport. In the conducted experiments the thickness of the filter layer determined the rate of transport increase with hydraulic gradient $i$ (steepness of curve, exponent in formula (1) and (2)) whereas the filter stone diameter determined the minimum amount of transport (factor $\mathrm{p}_{\mathrm{i}}$ in formula):

- The influence of the hydraulic gradient (and the filter velocity) is small for small (minimal) filter thicknesses, independent of filter stone diameter. The influence grows rapidly with larger filter thicknesses.

- The same influence can also be detected for the wave steepness: Wave steepness has only minor influence for small filter layers (independent of filter stone diameter). The influence grows rapidly with larger filter thicknesses. The maximum transport is found for low wave steepness.

The given formulae for transport (under stationary current, (1) and (2)) result in transport rates which are consistently larger than the values found for oscillatory flow, by a factor of 30-100. Also, the influences of both filter thickness and stone diameter are not included in these formulae so far. Thus, by taking into account the described linear trends for filter thickness and stone diameter, a new tentative relationship has been developed (valid in the experimental range: $\mathrm{D}_{\mathrm{n} 50, \mathrm{f}} / \mathrm{D}_{\mathrm{n} 50, \mathrm{~b}}=150$ $\left.230, \mathrm{~d} / \mathrm{D}_{\mathrm{n} 50}=1.8-3.3, \mathrm{~d} / \mathrm{h}=0.14-0.25, \mathrm{KC}=40-450\right)$, where $\mathrm{D}_{\mathrm{n} 50}=$ median nominal filter stone diameter $(\mathrm{m}), \mathrm{d}=$ filter thickness $(\mathrm{m}), \mathrm{h}=$ water depth $(\mathrm{m})$ and $\mathrm{T}=$ transport $(\mathrm{kg} / \mathrm{m} / \mathrm{s})$; see also Figures 3 and 4 :

$$
T_{1}=\rho_{s} \cdot p_{1} \cdot\left(i_{2 \%} / i_{c r}-1\right)^{x} \quad \begin{aligned}
& \text { with } p_{1}=1.5 \cdot 10^{-5} \cdot d^{2.3} \cdot\left(3.8-d / D_{n 50}\right), \\
& \text { and } x=21.3 \cdot \mathrm{d}-1.1 \text { with } \mathrm{x} \geq 0.05
\end{aligned}
$$

Similar trends were observed for the velocities (where $\mathrm{u}_{\mathrm{f}}$ is replaced here by the near-bed characteristic velocity $\mathrm{u}_{2 \%}$ measured $1 \mathrm{D}_{\mathrm{n} 50}$ above the filter layer):

$$
T_{2}=\rho_{s} \cdot p_{2} \cdot\left(\left(u_{2 \%} / u_{f . c r}\right)^{2}-1\right)^{x} \quad \begin{aligned}
& \text { with } p_{2}=3.4 \cdot 10^{-7} \cdot d \cdot\left(3.8-d / D_{n 50}\right), \\
& \text { and } x=5 \cdot \mathrm{d}-0.25 \text { with } \mathrm{x} \geq 0.05
\end{aligned}
$$


These transport relationships describe the total load transport of bed load and suspended load. Most of the material is transported in suspended load, the fraction transported by bed load transport appears negligible under waves.

A preference is given to the relationship for $\mathrm{i} / \mathrm{i}_{\mathrm{cr}}$ since the filter velocities $\mathrm{u}_{\mathrm{f}}$ inside the filter were not actually measured in this study (the relationship is based on the velocities measured just above the filter), whereas $i$ and $i_{c r}$ have been directly measured at the sand-filter interface.

The above presented (tentative) relationships still need verification and extension to a larger range of applicability, since they are based on only a few tests so far. Further testing is needed.

\section{CONCLUSIONS}

The presented hydraulic model study of a submerged filter structure on a horizontal sand bed shows that under wave influence large amounts of base material are set into motion within the filter and suspended in the water column, but not much is actually transported (factor of 30-100 less than the formulae predict for stationary currents). It is expected that under combined current + wave influence much of this stirred up material will be transported, resulting in possibly much larger transport rates than under waves or currents alone.

\section{REFERENCES}

Bakker K.J., Verheij H.J., and de Groot M.B. (1994). "Design relationship for filters in bed protection". J. Hydraulic Eng., 120(9), 1082-1088.

CIRIA | CUR | CETMEF. (2007). "The Rock Manual: The use of rock in hydraulic engineering". 2nd edition, C683, CIRIA, London.

De Graauw A., Van der Meulen T., Van der Does de Bye M. (1983). "Design criteria for granular filters", Publication 287, Delft Hydraulics.

Den Adel H., Koenders M.A., Bakker K.J. (1994). "The analysis of relaxed criteria for erosion-control filters." Canadian Geotechnical Journal, Vol. 31, Nr. 6, pp. 829-840.

Den Adel H. (1992). "Transportmodel voor filters", Deel 1-3, report C0-325970/6, Delft Hydraulics.

Dixen, F.H., Sumer, B.M. and Fredsoe, J. (2008). "Suction removal of sediment from between armor blocks. II: waves", J. of Hydraulic Engineering, Vol 134, no 10, October 2008, ASCE.

Klein Breteler M. (1989). "Zandtransport in granulaire filters, horizontale stationaire stroming", report H869, Delft Hydraulics.

Klein Breteler M., Den Adel H., Koenders M.A. (1992). "Taludbekledingen van gezette steen, Ontwerpregels voor het filter", report M1795/H195, XXI, Delft Hydraulics \& Geo Delft.

Sumer, B. M., Cokgor, S., and Fredsøe, J. (2001). "Suction removal of sediment from between armor blocks." J. Hydraul. Eng., 127(4), 293-306.

Van Rijn L.C. (2005). "Principles of sedimentation and erosion engineering in rivers, estuaries and coastal seas", AQUA publications.

Verheij H.J., Hoffmans G.J.C.M., Den Adel H., Akkerman. G.J. (2009). “Interface stability of granular filterstructures", CUR (in preparation). 